\title{
VISÃO DOS ALUNOS E GESTORES DO ENSINO MÉDIO DO PERÍODO NOTURNO SOBRE A DISCIPLINA DE EDUCAÇÃO FÍSICA
}

\author{
Carlos Cesar Mendonça, Wagner Aparecido Caetano \\ Curso de Educação Física da Universidade do Oeste Paulista - UNOESTE, Presidente Prudente, SP.
}

\section{RESUMO}

Esta pesquisa investigou se há nas unidades escolares do período noturno, de ensino médio, aulas de Educação Física, conforme alude a Lei no 10.793, de 01 de dezembro de 2003. O levantamento dos dados foi realizado através de questionários (questões abertas e fechadas) direcionados a 98 alunos e 4 gestores pertencentes à Diretoria de Ensino de uma cidade do interior do Estado de São Paulo. Os resultados encontrados condizem com a hipótese inicial que afirma que as escolas de ensino médio noturno não cumprem a determinação da lei $n^{\circ}$ 10.793. Tabulados os dados, identificamos certa negligencia quanto ao ensino de Educação Física no período noturno contemplando as vantagens e contribuições desta disciplina na grade curricular. Concluímos conscientizando o leitor da significativa relevância para a escola, o aluno e a sociedade da prática regular de atividade física escolar.

Palavras-chaves: Educação Física, grade curricular, alunos, gestores.

\section{VIEW OF NIGHT SHIFT HIGH SCHOOL STUDENTS AND MANAGERS OF THE PHYSICAL EDUCATION} DISCIPLINE

\begin{abstract}
This research investigated whether there are at schools of the night shift, high school, physical education classes, as referred to Law No. 10,793, of December, 1st 2003. Data collection was conducted through questionnaires (open and closed asks) targeted at 98 students and 4 managers belonging to the Board of Education of interior city of São Paulo State. Our results are consistent with the initial hypothesis which states that night shift high school did not meet the determination of the law $n^{0} 10,793$. Tabulated data, we identified certain neglect about teaching physical education at night contemplating the benefits and contributions of this discipline in the curriculum. We conclude the reader aware of significant relevance to the school, the student and society of regular physical activity at school.
\end{abstract}

Keywords: Physical Education, grade curriculum, students, managers. 


\section{INTRODUÇÃO}

Está pesquisa verificou a atuação desta disciplina nas escolas publicas no período noturno. No decorrer desta pesquisa apresentamos as alterações sofridas na legislação que ampara a disciplina de Educação Física no período noturno, até chegar á versão atualmente em vigor. Foram relatados os benefícios que as aulas de Educação Física podem propiciar a cada indivíduo, mesmo aqueles que se enquadram na exceção, portanto dispensados e protegidos pela Lei. O presente trabalho veio responder se há aulas de Educação Física no período noturno e também se há, nas unidades escolares, registros oficiais que dispensam àqueles que se enquadram nas exceções da lei de obrigatoriedade da disciplina, assim como investigar se há por parte dos alunos interesse em participar das aulas de Educação Física mesmo sabendo que existe um aparato legal que os dispensa de freqüentar as aulas de Educação Física no período noturno. Refletimos também, sobre as causas da evasão dos alunos nas aulas de Educação Física no período noturno. Com apoio de questionários voltados aos gestores e alunos, colhemos informações que após tabulação e análises foram transformados em ferramentas, classificando este trabalho como quali-quantitativo.

\section{Educação Física no Brasil}

No decorrer da história da Educação Física, no Brasil, podemos encontrar vários autores dissertando sobre sua importância, finalidade e contribuição para a Educação (SILVA; VENÂNCIO, 2005; CARNEIRO, 2002). Notamos, já na década de 1960, na Lei de Diretrizes e Bases da Educação Nacional (LDB), principal lei relacionada à Educação, a preocupação dos especialistas em discutirem quanto à necessidade de inserção da disciplina de Educação Física no Ensino. A primeira Lei, no 4.024, de 20 de dezembro de 1961 é o princípio desta preocupação, nela já encontramos intrínseca a obrigatoriedade da Educação Física nos cursos de graus primários e médios até a idade de 18 anos (BRASIL, 1961). Porém, essa lei tinha como preocupação primordial a preparação física dos jovens para o ingresso no mercado de trabalho de forma produtiva (SILVA; VENÂNCIO, 2005).

Dez anos após, houve uma reformulação na LDB ocorrida em 1971 (Lei no 5.692, de 11 de agosto de 1971), onde a obrigatoriedade da Educação Física foi ampliada a todos os níveis e graus do processo de escolarização, porém, ainda com a intenção de preparação física de trabalhadores (SILVA; VENÂNCIO, 2005). Somente vinte e cinco anos após a LDB de 1971, ou seja, em 1996, a disciplina de Educação Física aparece como um Componente Curricular da grade educacional (Lei no 9.394, de 20 de dezembro de 1996) descrita da seguinte forma:

A Educação Física, integrada à proposta pedagógica da escola, é componente curricular da educação básica, ajustando-se às faixas etárias e às condições da população escolar, sendo facultativa nos cursos noturnos (BRASIL, 1996).

Notamos que desde a década de 1960 foram elaboradas propostas de alterações que tornavam a Educação Física de um componente facultativo para uma disciplina obrigatória ao currículo do ensino fundamental e médio. Esta alteração foi elaborada e realizada em 2001 no parágrafo $3^{\circ}$ do artigo $26^{\circ}$ da LDB, que inseriu a expressão "obrigatório" ao "componente curricular" Educação Física (BRASIL, 2001).

Carneiro (2002) realizou uma pesquisa com onze escolas públicas do município de Niterói onde obteve os pareceres dos diretores destas respectivas escolas. $\mathrm{Na}$ época a 
Educação Física, no período noturno, era facultativa. Os diretores das escolas decidiam se ofereceriam ou não a disciplina no quadro curricular do ensino médio no período noturno. Contudo na pesquisa de Carneiro surgiram algumas representações:

- Os diretores interpretavam a legislação que versava sobre a facultatividade da Educação Física (e conseqüentemente, a Resolução SEE no 2439/2001) de forma equivocada. Ao receberem a proposta da matriz curricular do ensino médio noturno e verificarem que as aulas de Educação Física haviam sido excluídas do quadro que especificava os componentes curriculares que fariam parte da grade, os diretores escolares entendiam que esta disciplina não deveria ser oferecida mais para o ensino médio noturno;

- Os diretores de escola não faziam força para garantir aos alunos do ensino médio noturno o direito de participarem das aulas de Educação Física por se sentirem amparados pela legislação que tornava facultativa a inclusão da disciplina neste turno de ensino;

- As escolas não apresentavam condições favoráveis para a inclusão da Educação Física no ensino médio noturno;

- Embora os diretores de escola descrevessem a disciplina de Educação Física como sendo de grande relevância para a formação de seus alunos, as disciplina que compunham a parte diversificada da matriz curricular eram as que tinham o objetivo de preparar o aluno para 0 mercado de trabalho, segundo concepção dos diretores, e a Educação Física não contribuía para esta preparação;

- Os diretores de escola justificaram também a não inclusão da disciplina de educação física no ensino médio noturno ao sustentarem o argumento de que esta disciplina iria contribuir para desgastar ainda mais o aluno, que vinha cansado do trabalho (CARNEIRO, 2002).

Sem grandes esforços, já é possível observar um desprestígio da disciplina de Educação Física por parte dos gestores escolares. Entendiam que a Educação Física não possuía tanta importância quando comparada a outras disciplinas (CARNEIRO, 2002). Os gestores entenderam que a disciplina de Educação Física não contribuiria de forma significativa em preparar o aluno para ser inserido no mercado de trabalho quando completassem seu período de formação. Sendo assim, inferiram que mais uma disciplina na grade curricular iria desgastar, ainda mais, os alunos que freqüentam esse turno escolar.

Contudo, a última alteração que a lei sofreu é a que está em vigor, Lei nำ10.793, de 01 de dezembro de 2003. Essa apresenta em maior plenitude as possíveis contribuições da disciplina de Educação Física à formação de pessoas (BRASIL, 2003).

llustramos abaixo algumas destas alterações realizadas na LDB no 10.793 que permitem em alguns casos específicos a dispensa dos alunos das aulas de Educação Física no período noturno. O que deve ser ressaltado é que estes casos devem ser considerados exceções e não regra.

É permitida a dispensa das aulas de Educação Física ao aluno (BRASIL, 2003):

I - que cumpra jornada de trabalho igual ou superior a seis horas (Incluído pela Lei $\mathrm{n}^{\circ}$ 10.793, de 01 de dezembro de 2003)

II - maior de trinta anos de idade (Incluído pela Lei no 10.793, de 01 de dezembro de 2003)

III - que estiver prestando serviço militar inicial ou que, em situação similar, estiver obrigado à prática da Educação Física (Incluído pela Lei $\mathrm{n}^{\circ}$ 10.793, de 01 de dezembro de 2003) 
IV - amparado pelo Decreto-Lei no 1.044 , de 21 de outubro de 1969 (Incluído pela Lei no 10.793, de 01 de dezembro de 2003)

V - (VETADO) (Incluído pela Lei no 10.793 , de 01 de dezembro de 2003)

VI - que tenha prole. (Incluído pela Lei no 10.793, de 01 de dezembro de 2003)

A partir desta resolução, Lei ํo 10.793 , a presente pesquisa promoveu um estudo sistemático sobre as orientações dadas à disciplina de Educação Física no período noturno, enumerando se:

- as escolas oferecem a disciplina no citado período;

- há registros oficiais que dispensam àqueles que se enquadram nas exceções da lei de obrigatoriedade;

- há por parte dos alunos interesse em participar das aulas de Educação Física;

- quais as justificativas dos gestores que oferecem ou que deixam de oferecer a disciplina em questão.

O trabalho será realizado junto às escolas e alunos do ensino médio do período noturno de escolas publicas da Diretoria de Ensino de uma cidade interior do Estado de São Paulo. O princípio motivador à nossa investigação é a lei que aponta caráter obrigatório das aulas de Educação Física no ensino médio no respectivo período, ou seja, existe um aparato legal que atende essa questão e ele deve ser criteriosamente observado.

Podemos, também, observar que a Lei no 10.793 relata que, quem cumpra jornada de trabalho igual ou superior a seis horas não é obrigado a freqüentar as aulas de Educação Física. Entendemos que uma das funções desta disciplina é despertar, desenvolver e aprimorar as forças físicas, morais, cívicas, psíquicas e sociais do educando e constitui um dos fatores básicos para a conquista das finalidades da educação (decreto no 69.450, de 1 de novembro de 1971). Caso haja escolas que não dispõem da disciplina de Educação Física, entenderemos que as mesmas não estão cientes dos benefícios que a disciplina pode oferecer, ou seja, ignoram as contribuições específicas e gerais que tanto a LDB quanto os PCNs desta ciência aludem com clareza e perspicácia.

É fato que há uma especificidade tanto na grade curricular do ensino noturno devido às características peculiares daqueles que freqüentam esse período.

[...] se pensarmos no ensino médio noturno, esse cotidiano vai apresentar um conjunto de características singulares, pois recebe um aluno que já está inserido na produção capitalista e que chega à escola já esgotado pelas lides do trabalho que o explora. Resultado disso é o grande índice de evasões, reprovações, desistências, fato que contribuiu para a formação de um contingente de força de trabalho cada vez mais se desqualificado, pois o que se aprende na escola nada tem a ver com o que vive no mundo do capital (CARVALHO, 1994).

A ciência Educação Física pode contribuir significativamente de forma positiva a esse cenário descrito por Carvalho (1994) pois, é possível apontarmos vários trabalhos, fundamentados nos PCNs (BRASIL, 1997) desta disciplina, que envolvem o aluno não só no desenvolvimento das habilidades físicascorpóreas, mas a Educação Física enquanto ciência do homem, antropológica, consegue abarcar o multifacetado campo de desenvolvimento cultural conforme afirma a resolução CONFEF:

Art. 1ㅇ O Profissional de Educação Física é especialista em atividades físicas, nas suas diversas manifestações ginásticas, exercícios físicos, desportos, jogos, lutas, capoeira, artes marciais, 
danças, atividades rítmicas, expressivas e acrobáticas, musculação, lazer, recreação, reabilitação, ergonomia, relaxamento corporal, ioga, exercícios compensatórios à atividade laboral e do cotidiano e outras práticas corporais, tendo como propósito prestar serviços que favoreçam 0 desenvolvimento da educação e da saúde, contribuindo para a capacitação e/ou restabelecimento de níveis adequados de desempenho e condicionamento físico corporal dos seus beneficiários, visando à consecução do bem estar e da qualidade de vida, da consciência, da expressão e estética do movimento, da prevenção de doenças, de acidentes, de problemas posturais, da compensação de distúrbios funcionais, contribuindo ainda, para consecução da autonomia, da auto-estima, da cooperação, da solidariedade, da integração, da cidadania, das relações sociais e a preservação do meio ambiente, observando os preceitos de responsabilidade, segurança, qualidade técnica e ética no atendimento individual e coletivo (CONFEF $n^{\circ}$ 046/2002).

Não precisamos de grandes análises para inferir que desprestigiar uma disciplina capaz de envolver essa gama de aspectos positivos ao desenvolvimento humano não é uma atitude que condiz com o ideal de educação e qualidade e vida (CONFEF $n^{\circ}$ 046/2002).

Também fica claro que 0 aluno que exerça qualquer tipo de trabalho pode encontrar nas aulas de Educação Física motivação, preparo e condicionamento para que assim continue efetivamente suas atividades ordinárias, ou seja, a Educação Física pode preparar o aluno trabalhador, ou não trabalhador, para o dia-a-dia (CONFEF n 046/2002).

Outra questão que nos atende à observação é quanto aos alunos que estão acima de 30 anos de idade. A estes a dispensa também é legal, ou seja, eles usufruem da não obrigatoriedade da freqüência. Isso nos leva a seguinte indagação: a pessoa que passar dos trinta anos de idade não pode fazer atividade física? Óbvio que não. Quantos artigos são escritos falando sobre os benefícios da atividade física para esta faixa etária a qual se enquadram estes alunos. Por que privá-los de usufruir dos benefícios oferecidos pela disciplina se podemos ver que a pratica regular de atividade física nesta idade é muito importante como, por exemplo, para a prevenção de varias doenças (OMS, 2003).

Cabe a essa pesquisa investigar os alunos que contemplam a dispensa das aulas de Educação Física no período noturno indagando sobre suas expectativas quanto ter ou não as respectivas aulas. De acordo com Oliveira (2001), que realizou uma pesquisa sobre o tema 'A Educação Física no ensino médio no período noturno: um estudo participante', não há empecilhos que possam justificar a ausência da disciplina de Educação Física no período noturno. Bássoli pode mostrar que havia interesse, por parte dos alunos, pela disciplina mesmo entendendo que a mesma acarretaria mudanças na então grade curricular.

Contudo, entende que há uma possibilidade significativa de explorar essa temática: aulas de Educação Física no período noturno. Hipóteses elaboradas previamente nos informam certa negligência quanto à disciplina de Educação Física neste período. Nossa proposta é investigar com rigor dois momentos que consideramos importantes: primeiro as Leis que fundamentam a disciplina de Educação Física, ou seja, a parte que está escrita e promulgada pelos órgão oficias; segundo a interpretação que as unidades escolares (gestores) fazem destas Leis, levando em consideração sua práxis (alunos), sua aplicabilidade. Portanto, a presente pesquisa 
pretende abarcar um campo teórico e prática da disciplina de Educação Física no período noturno.

\section{MÉTODOS}

O método de estudos foi a análise de documentos contidos nas 4 instituições de ensino publico da Diretoria de Ensino de uma cidade do interior do Estado de São Paulo, investigadas com o intuito de esclarecer o problema desta pesquisa. Sabemos que há (por Lei) a obrigatoriedade da disciplina de Educação Física (Lei no 10.793, de 01 de dezembro de 2003). Sendo assim se há escolas que não disponibilizam as aulas; se há alguém que não freqüente essas aulas, esse alguém deve ter um motivo explícito em documento. Foram abordados os gestores (diretores ou vice-diretor ou coordenador pedagógico) com questionários abertos de 3 questões. Assim, acreditamos que os 4 membros destas instituições tiveram a liberdade para expressar suas idéias. Também foi aplicado um questionário fechado contendo 10 perguntas e uma questão em aberto para que os alunos do ensino médio pudessem expressar suas opiniões. Foi aplicado o questionário nos alunos do ensino médio do período noturno de quatro escolas, sendo todos voluntários que assinaram um termo de consentimento livre e esclarecido). Os documentos foram analisados para constatar os motivos para a ausência. Essa pesquisa classifica-se como quali-quantitativa, pois suas inferências foram advindas de análise de documentos presentes nas unidades escolares, questionários direcionados aos alunos das séries observadas e representações dos gestores escolares. Por fim, os dados técnicos foram quantificados e os analisados interpretativamente.

Também é pertinente, com o intuito de esclarecer a metodologia adotada neste trabalho de pesquisa, citar Alves Mazzotti que nos esclarece sobre a dimensão de campo da pesquisa que contém dados qualitativos:

[...] descrições detalhadas de situações, eventos, pessoas, interações e comportamentos observados; citações literais do que as pessoas falam sobre suas experiências, atitudes, crenças e pensamentos; trechos ou íntegras de documentos, correspondências, atas ou relatórios de casos (PATTON apud ALVES-MAZZOTTI, 1999, p. 132).

\section{RESULTADOS}

Com a preocupação de não cometermos nenhum tipo de discriminação entre as escolas que contribuíram para o desenvolvimento desta pesquisa, formamos uma amostra generalizada composta por 98 alunos participantes. Esses alunos freqüentam o ensino médio no período noturno.

Analisando esta amostra obtivemos os seguintes resultados.

Tabela 1. Respostas objetivas dos alunos.

\begin{tabular}{l|c|c}
\hline PERGUNTAS / AFIRMAÇÕES & Sim (\%) & Não (\%) \\
\hline Alunos que trabalham. & $68(69,4)$ & $30(30,6)$ \\
\hline Alunos que tem filhos. & $4(4,1)$ & $94(95,9)$ \\
\hline Alunos que tem deficiência física. & $1(1,0)$ & $97(99,0)$ \\
\hline Alunos que foram perguntados se gostariam de ter aulas de educação física. & $18(18,4)$ & $80(81,6)$ \\
\hline $\begin{array}{l}\text { Alunos que assinaram um documento na instituição, que dispensa das aulas de } \\
\text { Educação Física. }\end{array}$ & $34(34,7)$ & $64(65,3)$ \\
\hline Alunos que gostariam de ter aulas de educação física. & $81(82,6)$ & $17(17,4)$ \\
\hline Alunos que conhecem os benefícios da educação física. & $76(77,5)$ & $22(22,5)$ \\
\hline Alunos que participariam das aulas de educação física. & $87(88,8)$ & $11(11,2)$ \\
\hline
\end{tabular}


Após a coleta dos dados e sua analise estatística, constatamos que nenhuma das escolas participantes deste trabalho de pesquisa executa a disciplina de Educação Física no período noturno, fato este deduzido previamente em nossa hipótese.

Também cabe relevância mencionar que, embora na prática as aulas de Educação Física não aconteçam, todas as escolas investigadas oferecem a disciplina em questão na sua grade curricular. Curiosamente a disciplina existe no formato de currículo, porém sua prática não acontece. Outro ponto que nos chamou a atenção é que por lei (Lei $n^{\circ}$ 10.793, de 01 de dezembro de 2003) (obrigatório) todos os alunos que possuem motivos e justificativas para a dispensa da disciplina de Educação Física, deveriam ter assinado documentos que solicitariam sua dispensa, porém apenas $37,7 \%$ do grupo entrevistado fizeram alusão a tal documento.

Nosso trabalho identificou uma relação paradoxal da opinião dos gestores sobre a disciplina de Educação Física, pois 50\% dos profissionais que diretamente estão ligados à gestão de uma unidade escolar entendem a importância e as contribuições dada aos educando pelas aulas efetivas de Educação Física. Porém, como tem sido praxe nas escolas, estas aulas não vêm acontecendo de fato, pois os que não a entendem como disciplina fundamental ao desenvolvimento físico-cognitivo justificam-se alegando a sobrecarga no horário noturno, assim com o desgaste físico do aluno acarretado pelas aulas práticas de Educação Física.

Não entendemos que haja um debate cuja parte seja inserida as aulas de Educação Física ou não no período noturno. O que entendemos é que realmente há um comodismo na estrutura do sistema que não se ateve a refletir sobre como, onde e quando inserir esta disciplina na prática escolar assim como todas as outras disciplinas já existentes. A visão dos gestores não encontra sustentação nas opiniões dos alunos que, de forma majoritária (82,6\%) mostram-se propensos e motivados a participar das aulas desta disciplina. Inclusive, cabe ressalva, em horários alternativos.

Ao falarmos em aplicar (pois, podemos constatar que já se encontra inserida a disciplina na grade curricular) estas aulas de Educação Física no período noturno, ressaltamos a visão que um dos gestores manifestou sobre sua realização: estas aulas acarretariam tumulto e indisciplina por parte dos alunos, pois o mesmo relata que os discentes não se interessam em realizar atividades, fora do ambiente de sala de aula. Podemos observar que este tipo de visão não é um caso isolado, pois, Carneiro (2002) realizou pesquisa sobre o tema em questão e obteve este tipo de resposta por parte dos gestores investigados. Porém, devemos levar em consideração que a lei que estava em vigor relatava que eram facultativas as aulas de Educação Física, sendo assim, caberia ao gestor a decisão de oferecê-las ou não. Mas a lei que apóia este nosso trabalho é de 2003, onde consta que é obrigatório a participação dos alunos nas aulas de Educação Física, sendo permitida a dispensa somente aqueles que se enquadram exceção da respectiva lei.

Entretanto a visão dos alunos pesquisados proporcionou a constatação de que há uma imagem contraria a dos gestores, pois $52 \%$ dos alunos pesquisados optaram por aulas práticas, o que indica que os alunos sentem a necessidade de freqüentar aulas fora do ambiente de sala. Na Figura 1 podemos também observar que $32,7 \%$ querem aulas teóricas e práticas e apenas $4,1 \%$ querem somente as aulas teóricas e o restante da amostra dos alunos, ou seja, 11,2\% responderam que não querem aulas de Educação Física no período noturno. 


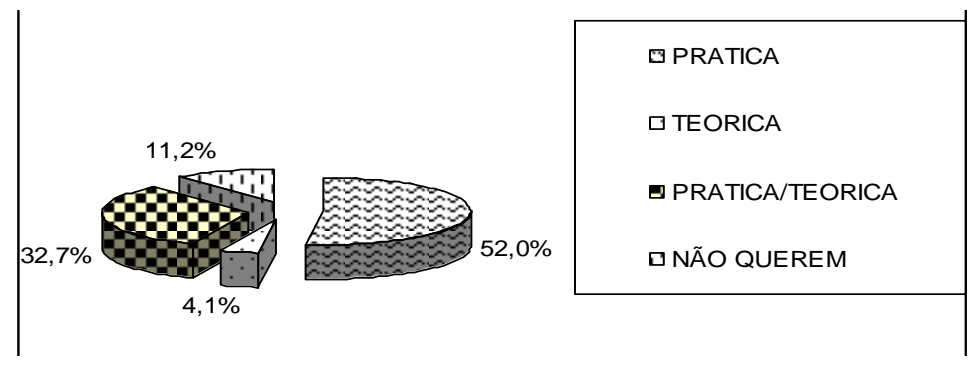

Figura 1. Preferência dos alunos pelas aulas de Educação Física.

Outro dado interessante foi que $77,5 \%$ dos alunos entrevistados sabem quais são os benefícios das aulas de Educação Física, assim também a mesma resposta foi encontrada na opinião da maior parte dos gestores, pois, tanto os decentes quanto os coordenadores pedagógicos das escolas enfatizam a significativa prática singular de atividade física, assim como seu conhecimento teórico.

A análise do questionário aplicado também nos informou, com clareza, que mesmo aqueles alunos que poderiam gozar da dispensa das aulas de Educação Física, pois estão aparados pela lei, como por exemplo, por trabalharem mais de seis horas por dia, gostariam de participar efetivamente das aulas de Educação Física. Entre eles, $69,4 \%$ é a proporção dos que afirmam que 0 trabalho não acarretaria em desinteresse a relação à prática nessa disciplina.

Outra informação interessante extraída da amostra deste trabalho relatou que $34 \%$ dos alunos entrevistados afirmam ter ciência de apresentar aos gestores da unidade escolar a qual freqüenta um comprovante que justifica a sua ausência das aulas de educação física pelos motivos contemplados pela lei 10.793. Esses mesmos alunos seriam dispensados da freqüência da disciplina sem prejuízos burocráticos a sua formação escolar.

Outro ponto que cabe à nossa reflexão é quanto ao número baixo que se refere aqueles que, por causas naturais, não podem ou não teriam condições físicas de participar das aulas práticas de Educação Físicas. Apenas 1\% da amostra relata possuir algum tipo de deficiência física e, apenas $4,1 \%$ possuem prole.

$\mathrm{Na}$ visão dos alunos quanto às aulas de Educação Física, observamos muito mais motivos que poderiam levá-lo a tê-las do que o contrário, como vem acontecendo nas unidades escolares.

Em números, apenas $17,4 \%$ se consideraram desmotivados a tal prática. Os demais participantes desta amostra pensam de forma contraria.

Referente ao fator idade, aqueles que possuem mais de 30 anos são também, dispensados das aulas de Educação Física, não foi encontrado nenhum na amostra. $O$ que foi obtido é que $78,54 \%$ dos alunos têm idade abaixo de 18 anos e a máxima que foi encontrada foi 23 anos.

Os gestores responderam a três questões dissertativas possibilitando, assim, opinarem com mais liberdade sobre o tema em questão. A título de esclarecimento e conhecimento do leitor, optamos em reproduzir as respostas dos gestores na íntegra com a intenção de propiciar um conhecimento amplo sobre a visão dos gestores educacionais quanto à disciplina de Educação Física no período noturno, ponto crucial e norteador do desenvolvimento deste trabalho. 


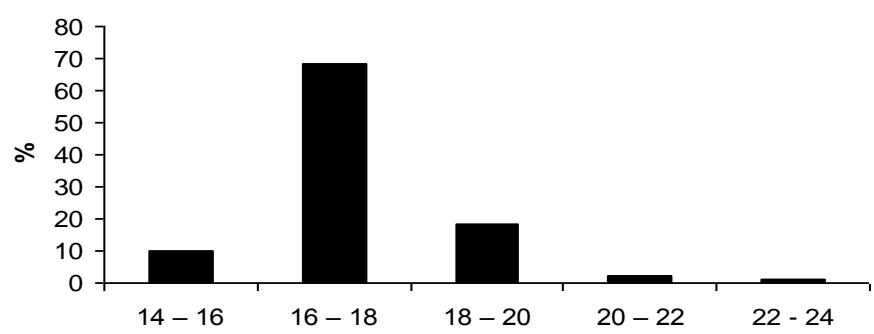

Figura 2. Frequência de idade dos alunos.

1ํ pergunta: Qual a sua visão sobre a educação física no ensino médio no período noturno mesmo sabendo que existe um aparato legal que dispensam os alunos que se enquadram na respectiva lei $n \circ 10.793$, de 01 de dezembro de 2003?

Respostas obtidas:

- Que esta disciplina não é viável no período noturno para o nosso tipo de clientela principalmente porque são alunos trabalhadores e não poderiam frequentar a mesma em horário diverso. Além do que, o início das aulas teria que ser antecipado por não fazer parte da grade atual no mesmo período das aulas.

- A Educação Física no período noturno destinada aos alunos do ensino médio é benéfica não apenas para o corpo, mas também para a mente e melhora o rendimento escolar. Ela apresenta características próprias, trabalha as suas próprias especificidades e se inter-relaciona com outros componentes curriculares. O poder de adequação do conteúdo ao grupo social em que é trabalhado permite uma liberdade de trabalho que é benéfica ao processo educacional do aluno.

- A Educação Física no período noturno seria boa com efeito na conscientização da atividade física da saúde.

- Sendo uma disciplina que trabalha a cultura relacionada aos aspectos corporais que se expressa de diferentes formas: os jogos, a ginástica, as danças e atividades rítmicas, as lutas e os esportes, é importante que essa informação chegue a todos os jovens.

$2^{\text {a }}$ pergunta: $O$ que você pensa que mudaria se as aulas de Educação Física existissem no período noturno?

Respostas obtidas:

- Maior participação dos alunos nas atividades contextualizadas e diversificadas proporcionadas no âmbito escolar.

- Nada mudaria, claro se essas aulas fossem realizadas de maneira única para o grupo. - Penso que haveria mais indisciplina e tumulto na escola porque os alunos se recusam a qualquer atividade fora da sala de aula mesmo que seja gincana, palestras ou teatro.

- O aluno trabalhador, após uma jornada de oito horas de trabalho, desloca-se a escola e deposita nela a esperança de poder mudar de vida. Desta forma, acredita-se que a Educação Física no período noturno possa representar um espaço de ruptura do tempo de trabalho possibilitando manter um mínimo de qualidade de vida.

3ำ pergunta: Em sua opinião, por que não oferecer as aulas de Educação Física à noite?

Respostas obtidas:

- $\quad$ Entendemos que a Educação Física no período noturno não é praticada, mas faz parte do currículo oficial, apenas porque dispensam os alunos que se enquadram na lei no 10.793 , de 01 de dezembro de 2003. 
- A maior desculpa dos discentes é o fato de dizerem estar cansados. E o próprio horário é curto para pensar em uma atividade de 50 minutos.

- Porque acredito que eles não aproveitariam esta aula devido ao cansaço. A maioria dos alunos do sexo masculino do período noturno trabalha no corte de cana ou são serventes de pedreiro e as do sexo feminino são empregadas domésticas.

- Sou a favor, pois desperta a criatividade, se sentem mais motivados para freqüentar as aulas, diminuindo a evasão e conseqüentemente a repetição.

\section{DISCUSSÃO}

É fato que há características que diferem ao compararmos os discentes do ensino médio do período noturno com aqueles que freqüentam as aulas no período matutino e vespertino. Essas mesmas particularidades exigem da gestão escolar adequação, que possam enquadrar essas diferenças sem que haja mudanças na proposta do currículo do ensino médio nacional.

Também fica evidente que o problema alcança dimensões que extrapolam qualquer tipo de reducionismo quanto a sua solução, ou seja, envolve tanto um sistema complexo de ensino que começando pelos alunos chegam até os teóricos da educação e vice-versa.

Porém, também, cabe exaltarmos nesta parte do trabalho os benefícios advindos da prática regular da atividade física, lembrando que essa prática é possível de ser realizada nas escolas, nas próprias aulas de Educação Física, ministradas pelos respectivos professores (licenciados).

Apontamos alguns destes benefícios já alertando que se somam a eles muitos outros de igual ou maior significância. A saber: a relação entre Educação Física e saúde; a Educação Física e o trabalho de condicionamento físico; a
Educação Física e a socialização e, por fim, a Educação Física e aquisição de conteúdo prático e teórico.

A American Alliance for Health, Physical Education Recreation and Dance (AAHPERD, 1980), Monteiro (1996), Nahas (2001) e Caspersen et al. (1985) citam alguns benefícios, relacionados à saúde que a Educação Física proporciona para seus praticantes: resistência aeróbica, força muscular, composição corporal, resistência muscular e flexibilidade. Tais benefícios acarretam, como conseqüência, crescimento, desenvolvimento e envelhecimento saudável do individuo. Sendo assim, torna-se evidente que aqueles que não a praticam ou são privados pelo próprio sistema educacional, estão agindo contra as expectativas de uma vida continua e saudável.

Para aqueles que alegam sobrecarga ao relacionar 0 trabalho diário a dispensa ou ausência das aulas de educação física, mencionamos a importância advinda da prática regular de uma atividade física orientada no quesito qualidade de vida. Romero (2009) ao realizar uma pesquisa envolvendo alunos do EJA (Educação de Jovens e Adultos) no período noturno chegou à conclusão que os alunos que freqüentam aulas de Educação Física no período noturno interagem efetivamente com a proposta da disciplina alegando, ainda, que é neste momento que se sentem livres das cobranças rotineiras de seus trabalhos. Os discentes exaltam, também, que é neste momento que é possível movimentar-se de forma antagônica a automação dos trabalhos realizados fora da escola. Romero ainda destaca o relacionamento saudável, amigável entre os discentes e seus professores. Tal observação descarta a questão de indisciplina e desgaste por parte dos alunos, indo na contra-mão do discurso proferido por alguns gestores escolares já apresentados neste trabalho. 
Contudo, cabe alusão aos conhecimentos práticos e teóricos que podem ser construídos nas aulas de Educação Física. Segundo o CONFEF ( $n^{\circ}$ 046/2002) o profissional de Educação Física pode contribuir para 0 desenvolvimento de várias habilidades culturais, históricas e antropológicas que possibilitarão o melhor entendimento e aplicabilidade por parte dos discentes em sua rotina diária e acadêmica. Sendo uma ciência do físico e do cultural, as aulas de Educação Física possuem um universo de temas e conhecimentos que podem ser desenvolvidos e construídos tanto no ambiente sala de aula como na quadra, durante a prática de exercícios.

\section{CONCLUSÃO}

\begin{abstract}
Mediante aos dados e análises apresentados acima, adotamos como caráter conclusivo a necessidade e a inserção da disciplina de Educação Física no período noturno. Esse trabalho nos conduz a um número maior de benefícios, isso comparando aos possíveis obstáculos, que essa disciplina pode proporcionar a vida dos alunos e ao ensino em si. O fato é que a disciplina já se encontra inserida no quadro geral de matérias a serem lecionadas, porém, na prática, isso não vem acontecendo. Se desejamos um ensino de maior relevância e significado, enxergamos na disciplina de Educação Física uma possibilidade palpável para alcançar esse ideal.
\end{abstract}

\section{REFERÊNCIAS}

Alves-Mazzotti AJ. O método nas ciências sociais. In: Alves-Mazzotti JA, Gewandsznajder F. O método nas ciências naturais e sociais: pesquisa quantitativa e qualitativa. 2ed. São Paulo: Pioneira; 1999.

American Alliance for Health, Physical Education Recreation and Dance - AAHPERD, 1980.
Brasil. Presidência da República. Lei no 4.024, de 20 de dezembro de 1961. Diário Oficial, Brasília, 27 dez. 1961.

Brasil. Presidência da República. Lei no 5.692, de 11 de agosto de 1971. Diário Oficial, Brasília, 12 ago. 1971 .

Brasil. Presidência da República. Lei no 9.394, de 20 de dezembro de 1996. Diário Oficial, Brasília, 23 dez. 1996.

Brasil. Presidência da República. Lei no 10.328, de 12 de dezembro de 2001. Diário Oficial, Brasília, 13 dez. 2001.

Brasil. Presidência da República. Lei no 10.793, de 01 de dezembro de 2003. Diário Oficial, Brasília, 2 dezembro 2003.

Brasil, Secretaria da Educação Fundamental. PCN (Parâmetros Curriculares Nacionais): Educação Física/BRASÍLIA-SP/MEC/SEF, 1997.

Carneiro EB. Representação Social de diretores de Escolas Públicas de Niterói sobre a inclusão da Educação Física no ensino médio noturno. Dissertação (Mestrado em Educação Física). Rio de Janeiro: Universidade Gama Filho, 2002.

Carvalho CP. Ensino noturno: realidade e ilusão. 7ed. São Paulo: Cortez; 1994.

Caspersen CJ, Powell JE, Chiristenson GM. Physical activity, exercise, and physical fitness: definitions and distinctions for health-related research. Public Health Reports 1985; 100(2):126-131.

Conselho Federal de Educação Física CONFEF. Resolução CONFEF no 046/2002. Rio de Janeiro, 18 de Fevereiro de 2002.

Decreto oㅡ 69.450, de 1 de novembro de 1971, Art. $1^{\circ}$.

Monteiro WD. Aspectos fisiológicos e metodológicos físico na promoção da saúde. Revista Brasileira de Atividade Física e Saúde 1996; 3(1):44-58.

Nahas MV. Atividade Física, saúde e qualidade de vida: conceitos e sugestões para um estilo de vida ativo. Londrina: Midiograf; 2001.

Oliveira AAB. A Educação Física no ensino médio no período noturno: um estudo participante, Movimento 2001; ano $\mathrm{VI}(12)$.

Organização Mundial da Saúde, Comunicado de Imprensa conjunto da OMS/FAO 32. 23 de Abril 2003. 
Romero WA. Programa de condicionamento físico: Uma proposta de atividade física para alunos do EJA. 2009.

Silva EVM, Venâncio L. Aspectos legais da Educação Física e integração á proposta pedagógica da escola. In: Darido SC, Rangel ICA (Coord.). Educação Física na escola: implicações para a prática pedagógica. Rio de Janeiro: Guanabara Koogan; 2005. p.50-63. 